\title{
Gender and survival of critically ill patients: results from the FROG-ICU study
}

\author{
Alexa Hollinger 1,2,3, Etienne Gayat ${ }^{1,2}$, Elodie Féliot ${ }^{1,2}$, Catherine Paugam-Burtz ${ }^{4}$, Marie-Céline Fournier ${ }^{1,2}$, \\ Jacques Duranteau ${ }^{5}$, Jean-Yves Lefrant ${ }^{6}$, Marc Leone ${ }^{11}$, Samir Jaber ${ }^{7,8}$, Alexandre Mebazaa ${ }^{1,2,10^{*+}}$, Mattia Arrigo ${ }^{9 \dagger}$ \\ and On behalf of the FROG ICU study investigators
}

\begin{abstract}
Purpose: Few studies analyzed gender-related outcome differences of critically ill patients and found inconsistent results. This study aimed to test the independent association of gender and long-term survival of ICU patients.

Materials and methods: FROG-ICU was a prospective, observational, multi-center cohort designed to investigate the long-term mortality of critically ill adult patients. The primary endpoint of this study was 1-year mortality after ICU admission of women compared to men.

Results: The study included 2087 patients, 726 women and 1361 men. Women and men had similar baseline characteristics, clinical presentation, and disease severity. No significant difference in 1-year mortality was found between women and men $(34.9 \%$ vs. $37.9 \%, P=0.18)$. After multivariable adjustment, no difference in the hazard of death was observed [HR 0.99 (95\% Cl 0.77-1.28)]. Similar 1-year survival between women and men was found in a propensity score-matched patient cohort of 506 patients [HR 0.79 (95\% Cl 0.54-1.14)].
\end{abstract}

Conclusion: Women constituted one-third of the population of critically ill patients and were unexpectedly similar to men regarding demographic characteristics, clinical presentation, and disease severity and had similar risk of death at 1 year after ICU admission.

Trial registration ClinicalTrials.gov NCT01367093; registered on June 6, 2011.

Keywords: Gender, Female, Women, Critically ill, ICU, Mortality, Outcome

\section{Introduction}

Critically ill patients display in-hospital mortality rates up to $20-40 \%,[1-3]$ as well as impaired long-term survival and quality of life $[4,5]$. Most ICU trials investigating outcome focused mostly on short-term survival with little regard for long-term outcome and studied the population of critically ill patients as a whole, neglecting potential differences associated with gender.

Few studies analyzed gender-related differences in short- and long-term mortality of ICU patients and

\footnotetext{
*Correspondence: alexandre.mebazaa@aphp.fr

${ }^{\dagger}$ Alexandre Mebazaa and Mattia Arrigo equally contributed as senior author

${ }^{10}$ Department of Anesthesiology and Intensive Care, Saint Louis Lariboisière University Hospitals, 2 rue Ambroise Paré, 75010 Paris, France Full list of author information is available at the end of the article
}

found inconsistent results. A large Swedish ICU study showed that male gender was associated with higher consumption of ICU resources and longer ICU stay, but with similar short-term mortality compared to women [6]. On the contrary, male gender was associated with improved in-hospital survival in a study on sepsis and septic shock [7]. Other ICU studies did not find relevant differences in short- and long-term survival between women and men $[8,9]$.

Even fewer data are available for gender-related differences in long-term survival after critical illness. Moreover, long-term survival is mostly dependent on the burden of comorbidities after ICU discharge, which may vary across genders, as recently described by our group and others $[5,9]$. Therefore, whether the gender itself or the associated demographic and clinical characteristics 
may influence the long-term survival of critically ill patients is unknown.

The primary aim of this French and euRopean Outcome reGistry in Intensive Care Unit (FROG-ICU) sub-study was to test the hypothesis that gender is independently associated with long-term survival of critically ill patients.

\section{Materials and methods \\ Study design}

FROG-ICU was a prospective, observational, multicenter cohort designed to investigate long-term mortality of critically ill adult patients. The study was performed in accordance with Good Clinical Practice and the Declaration of Helsinki 2002, validated by the corresponding ethical committees and registered on ClinicalTrials.gov (NCT01367093). Patients were recruited from August 2011 to June 2013.

The study design was published previously [10]. Briefly, all consecutive patients admitted to any of the 28 participating ICUs in 19 hospitals in France and Belgium were screened for eligibility. Inclusion criteria were requirement for invasive mechanical ventilation and/or vasopressor or inotrope drug support for more than $24 \mathrm{~h}$ following ICU admission. Exclusion criteria were age less than 18 years, severe head injury, brain death or persistent vegetative state, organ transplantation in the last 12 months and/or lack of social security coverage.

The primary endpoint of this study was 1-year mortality. The secondary endpoint was 28 -day mortality.

\section{Statistical analysis}

Continuous variables are expressed as median (interquartile range), and nominal variables are expressed as number (percentages). Differences between independent groups were assessed with Wilcoxon rank sum test, Mann-Whitney $U$-test, and Fisher's exact test, as appropriate.

Survival was plotted with the Kaplan-Meier curve, and differences between groups were tested with the log-rank test. Unadjusted and covariate-adjusted Cox proportional hazards models were used to evaluate the association between gender and 1-year mortality, resp. 28-day mortality after ICU admission. The relative hazard is expressed as hazard ratio (HR) with 95\% confidence interval (CI). Adjustments were performed for Simplified Acute Physiology Score II (SAPS II), Sequential Organ Failure Assessment (SOFA) score, and Charlson Comorbidity Index (CCI). Subgroup analyses were performed for age (below vs. above the median) and diagnosis groups at ICU admission.

To further reduce the bias related to the difference in baseline characteristics between women and men, the primary and secondary endpoints were investigated in a propensity score-matched cohort.

To create a propensity score on gender, gender was explained by the following clinical variables: age, body mass index, SAPS II, Glasgow coma scale, heart rate, mean blood pressure, temperature, $\mathrm{pH}$, hemoglobin, platelets, white blood count, creatinine, urea at inclusion, diagnosis at inclusion (heart failure/cardiogenic shock/sepsis/neurological disease/hemorrhagic shock/ trauma/postoperative), Charlson Comorbidity Index, hypertension, dyslipidemia, diabetes mellitus, smoking status, alcohol status, coronary artery disease, valvular heart disease, chronic heart failure, peripheral vascular disease, prior stroke, cognitive dysfunction, loss of autonomy, chronic obstructive pulmonary disease, chronic liver disease, chronic renal disease, renal replacement therapy, malignancy, human immunodeficiency virus infection, acute respiratory insufficiency, tracheostomy. Ratio for matching was to 1 for 1 (one man associated with one women) with a caliper of $20 \%$, using the "nearest neighbor" method. Standardized difference of mean or prevalence between men and women is calculated for each covariate of propensity score to check whether characteristics between groups are well balanced. Matching was accepted when all standardized differences were smaller than $10 \%$. The matching process significantly reduced differences in baseline characteristics (see Additional file 1: Figure 1).

The null hypothesis was rejected with an adjusted twosided $P$ value $<0.05$. All statistical analyses were performed using R statistical software (The "R" Foundation for Statistical Computing, Vienna, Austria).

\section{Results}

\section{Patient characteristics during ICU stay}

The study included 2087 patients, 726 women and 1361 men (Fig. 1). Patient characteristics are summarized in Table 1 . Women and men had globally similar baseline characteristics (i.e., age, burden of comorbidities, and Charlson Comorbidity Index), similar clinical presentation (i.e., blood pressure, heart rate, use of vasopressors, mechanical ventilation), and similar disease severity, according to SAPS II and SOFA score, as shown in Table 1. Significant differences between women and men were found with respect to some preexisting diseases, ICU referral diagnosis, laboratory parameters at admission, and the need for renal replacement therapy during ICU stay, as shown in Table 1. ICU mortality and length of stay were $21.7 \%$ and 12 [7;21] days, respectively, without relevant differences between women and men, as shown in Table 2. 


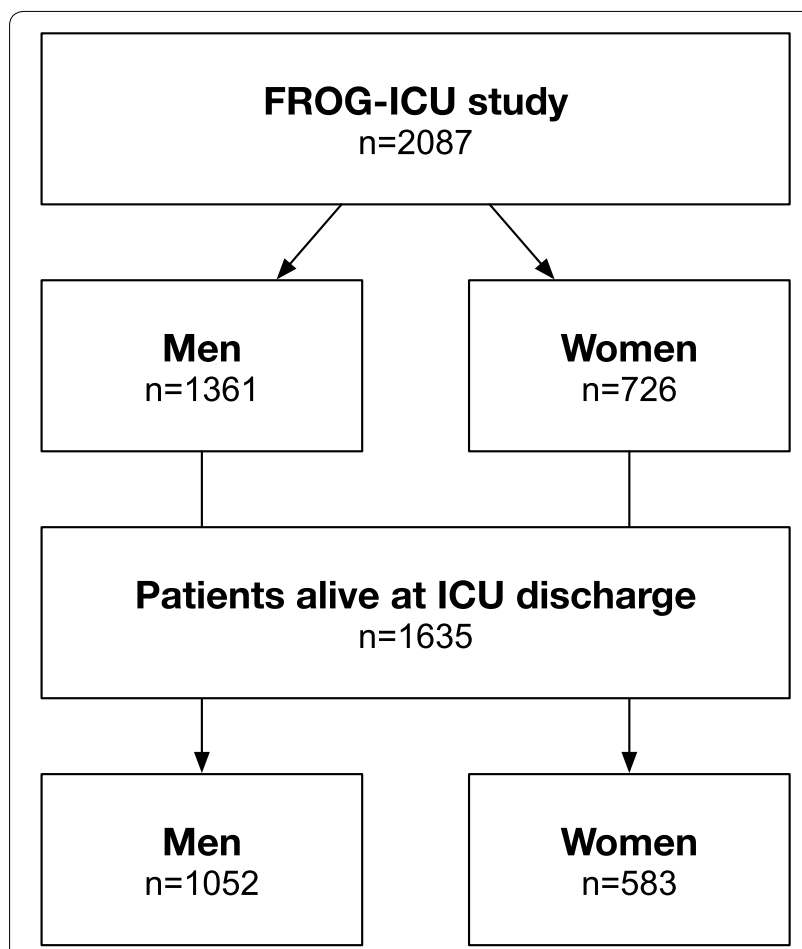

Fig. 1 Study population of the FROG-ICU cohort

\section{Primary endpoint (1-year mortality)}

No significant difference in 1-year mortality after ICU admission (34.9\% vs. $37.9 \%, P=0.18$ ) was found between women and men, as shown in Table 2. Accordingly, there was no difference in the hazard of death for women compared to men [HR 0.87 (95\% CI 0.72-1.06)], as shown in Fig. 2. After multivariable adjustment, no difference in the hazard of death was found [HR 0.99 (95\% CI 0.771.28)], as shown in Fig. 2.

Similar 1-year survival between women and men was found in a propensity score-matched patient cohort of 506 patients (Table 3, Fig. 3). Accordingly, the hazard of death at 1 year after ICU admission was similar for women compared to men in the matched cohort [HR 0.79 (95\% CI 0.54-1.14)], as shown in Fig. 2.

\section{Secondary endpoint (28-day mortality)}

No significant difference in survival was found between women and men at 28 days after ICU admission (19.2\% vs. $22.4 \%, P=0.09$ ), as shown in Table 2. Accordingly, there was no difference in the hazard of death for women compared to men [HR 0.82 (95\% CI 0.65-1.02)], as shown in Fig. 2. After multivariable adjustment, no difference in the hazard of death was found [HR 1.08 (95\% CI 0.79-1.47)], as shown in Fig. 2.
Consistent results were found in the propensity scorematched cohort of 506 patients (Table 3) with no difference in the hazard of death at 28 days after ICU admission between women and men [HR 0.70 (95\% CI 0.44-1.11)], as shown in Fig. 2.

\section{Subgroup analysis}

As depicted in Fig. 4, consistent results with similar survivals of women compared to men at both 1 year and 28 days after ICU admission were found, independently from the diagnosis at ICU admission. Notably, we observed a trend toward reduced hazard of death for older women compared to older men, in particular at 28 days after admission, as shown in Additional file 1: Figure 2.

\section{Discussion}

Few studies analyzed gender-related differences in outcome of critically ill patients and found inconsistent results. This study aimed to test the hypothesis that gender is independently associated with long-term survival in a large, prospective, multi-centric cohort of critically ill patients. We found that women have similar long-term survival after ICU admission, compared to men.

First, the population of our study consisted of critically ill patients with relevant ICU mortality, in line with previous studies. Our study showed that women and men have some relevant differences in ICU referral diagnosis and comorbidities, as previously described and long known $[11,12]$. However, and even more notably, women and men were unexpectedly similar regarding demographic characteristics, clinical presentation, disease severity, and ICU outcomes. Despite these similarities in baseline characteristics and outcome, and the effort to include all consecutive patients fulfilling inclusion criteria, we observed that only one of three patients included in our study was a woman. The reason for this imbalance is unknown but will require further investigations. We might anticipate that a combination of several factors, including gender-related variations in clinical presentation of disease, diverging patients' preferences, and variable attitude of the treating teams, may have led to this imbalanced rate of ICU admissions.

Second, we observed consistently similar survival in women and men at both 28 days and 1 year after ICU admission. Survival remained similar after multivariable adjustment for comorbidities and disease severity and also in the propensity score-matched cohort to obviate difference in baseline characteristics. The impact of gender on prognosis has been thoroughly assessed in cardiology [13-24] and psychiatry [25-31], whereas most previous studies with critically ill patients analyzed the population as a whole, with little regard to gender-related 
Table 1 Patient characteristics at ICU admission

\begin{tabular}{|c|c|c|c|c|}
\hline Patient characteristics & $\begin{array}{l}\text { All } \\
N=2087\end{array}$ & $\begin{array}{l}\text { Women } \\
N=726\end{array}$ & $\begin{array}{l}\text { Men } \\
N=1361\end{array}$ & $P$ value* \\
\hline \multicolumn{5}{|l|}{ Demographic data } \\
\hline Age (year) & $63[51 ; 74]$ & $63[51 ; 74.8]$ & $63[51 ; 74]$ & 0.59 \\
\hline Body Mass Index (kg/m2) & $26.5[23.1 ; 30.8]$ & $26[22.5 ; 31.2]$ & $26.6[23.5 ; 30.3]$ & 0.51 \\
\hline \multicolumn{5}{|l|}{ Comorbidities } \\
\hline Hypertension & $902(43.3 \%)$ & $319(43.9 \%)$ & $583(43 \%)$ & 0.67 \\
\hline Dyslipidaemia & $412(19.8 \%)$ & $123(16.9 \%)$ & $289(21.3 \%)$ & 0.017 \\
\hline Diabetes melllitus & $384(18.4 \%)$ & $121(16.7 \%)$ & $263(19.4 \%)$ & 0.13 \\
\hline Coronary artery disease & $188(9 \%)$ & $35(4.8 \%)$ & $153(11.3 \%)$ & $<0.001$ \\
\hline Valvular heart disease (severe) & $82(3.9 \%)$ & $31(4.3 \%)$ & $51(3.8 \%)$ & 0.57 \\
\hline Heart failure & $153(7.3 \%)$ & $57(7.9 \%)$ & $96(7.1 \%)$ & 0.52 \\
\hline Peripheral vascular disease & $209(10 \%)$ & $60(8.3 \%)$ & $149(11 \%)$ & 0.05 \\
\hline Prior stroke & $92(4.4 \%)$ & $25(3.4 \%)$ & $67(4.9 \%)$ & 0.11 \\
\hline COPD & $273(13.1 \%)$ & $70(9.6 \%)$ & $203(15 \%)$ & 0.001 \\
\hline Chronic kidney disease & $241(11.6 \%)$ & $80(11 \%)$ & $161(11.9 \%)$ & 0.57 \\
\hline Chronic liver disease & $158(7.6 \%)$ & $52(7.2 \%)$ & $106(7.8 \%)$ & 0.59 \\
\hline Active malignant tumors & $281(13.5 \%)$ & $93(12.8 \%)$ & $188(13.9 \%)$ & 0.51 \\
\hline HIV & $53(2.5 \%)$ & $12(1.7 \%)$ & $41(3 \%)$ & 0.06 \\
\hline Loss of autonomy & $78(3.7 \%)$ & $38(5.2 \%)$ & $40(2.9 \%)$ & 0.009 \\
\hline Cognitive dysfunction & $33(1.6 \%)$ & $13(1.8 \%)$ & $20(1.5 \%)$ & 0.58 \\
\hline \multicolumn{5}{|l|}{ Diagnosis at ICU admission } \\
\hline Respiratory disorder & $89(4.3 \%)$ & $21(2.9 \%)$ & $68(5 \%)$ & 0.017 \\
\hline Trauma & $536(25.7 \%)$ & $182(25.1 \%)$ & $354(26 \%)$ & \\
\hline Sepsis/septic shock & $179(8.6 \%)$ & $53(7.3 \%)$ & $126(9.3 \%)$ & \\
\hline Neurological disease & $286(13.7 \%)$ & $120(16.5 \%)$ & $166(12.2 \%)$ & \\
\hline Cardiac arrest & $394(18.9 \%)$ & $142(19.6 \%)$ & $252(18.5 \%)$ & \\
\hline Cardiogenic shock & $146(7 \%)$ & $55(7.6 \%)$ & $91(6.7 \%)$ & \\
\hline Hemorrhagic shock & $110(5.3 \%)$ & $31(4.3 \%)$ & $79(5.8 \%)$ & \\
\hline Planned surgery & $165(7.9 \%)$ & $52(7.2 \%)$ & $113(8.3 \%)$ & \\
\hline Others & $181(8.7 \%)$ & $70(9.6 \%)$ & $111(8.2 \%)$ & \\
\hline \multicolumn{5}{|l|}{ Vital parameters } \\
\hline Temperature $\left({ }^{\circ} \mathrm{C}\right)$ & $37.2[36.7 ; 37.8]$ & $37.2[36.7 ; 37.7]$ & $37.3[36.8 ; 37.9]$ & 0.001 \\
\hline Mean blood pressure $(\mathrm{mmHg})$ & $81.3[72.3 ; 92]$ & $81.3[72.3 ; 91.7]$ & $81.2[72.3 ; 92]$ & 0.81 \\
\hline Heart rate (bpm) & $92[78 ; 106]$ & $92[79 ; 106]$ & $91[77 ; 106]$ & 0.60 \\
\hline Glasgow coma scale & $14[5 ; 15]$ & $14[4 ; 15]$ & $14[5 ; 15]$ & 0.18 \\
\hline \multicolumn{5}{|l|}{ Laboratory values at admission } \\
\hline Arterial pH & $7.4[7.4 ; 7.5]$ & $7.4[7.4 ; 7.5]$ & $7.4[7.4 ; 7.5]$ & 0.12 \\
\hline Lactate $(\mathrm{mmol} / \mathrm{L})$ & $1.4[1 ; 2]$ & $1.4[1.1 ; 2]$ & $1.4[1 ; 1.9]$ & 0.09 \\
\hline Leukocytes (G/L) & $10.9[7.6 ; 16.2]$ & $11.6[8.2 ; 17]$ & $10.6[7.4 ; 15.8]$ & 0.004 \\
\hline Hemoglobin (g/L) & $100[89 ; 114]$ & $99[88 ; 109]$ & $101[90 ; 117]$ & $<0.001$ \\
\hline Platelets (G/L) & $164[99 ; 244]$ & $171[98 ; 257]$ & $162[101 ; 237]$ & 0.15 \\
\hline BUN or Urea $(\mathrm{mg} / \mathrm{dL})$ & $8.4[5.2 ; 14]$ & $7.1[4.4 ; 12.6]$ & $9.1[5.6 ; 14.8]$ & $<0.001$ \\
\hline Creatinine (mg/dL) & $84[59 ; 150]$ & $69[50 ; 119]$ & $94[66 ; 165]$ & $<0.001$ \\
\hline Bilirubin (umol/L) & $13[8 ; 27]$ & $11[7 ; 21]$ & $14[9 ; 29]$ & $<0.001$ \\
\hline \multicolumn{5}{|l|}{ Organ support } \\
\hline Vasopressors at admission & $1502(72.2 \%)$ & $526(72.5 \%)$ & $976(72 \%)$ & 0.84 \\
\hline \multicolumn{5}{|l|}{ Ventilation during ICU stay: } \\
\hline Invasive & $1632(80.3 \%)$ & $561(79.7 \%)$ & $1071(80.6 \%)$ & 0.76 \\
\hline Non-invasive & $316(15.6 \%)$ & $115(16.3 \%)$ & $201(15.1 \%)$ & \\
\hline RRT during ICU stay & $480(23 \%)$ & 137 (18.9\%) & $343(25.2 \%)$ & 0.001 \\
\hline
\end{tabular}


Table 1 (continued)

\begin{tabular}{lllll}
\hline Patient characteristics & $\begin{array}{l}\text { All } \\
\boldsymbol{N = 2 0 8 7}\end{array}$ & $\begin{array}{l}\text { Women } \\
\boldsymbol{N = 7 2 6}\end{array}$ & $\begin{array}{l}\text { Men } \\
\boldsymbol{N}=\mathbf{1 3 6 1}\end{array}$ \\
\hline Disease severity scores & & & & $\boldsymbol{P}$ value \\
Charlson score & $3[1 ; 5]$ & $3[1 ; 5]$ & $3[1 ; 5]$ & 0.15 \\
SAPS II & $49[36 ; 63]$ & $50[35 ; 62]$ & $48[36 ; 63]$ & 0.85 \\
SOFA score & $8[5 ; 10]$ & $7[5 ; 10]$ & $8[5 ; 11]$ & 0.12 \\
\hline
\end{tabular}

Data presented as median [interquartile range] and $P$ value obtained with Mann-Whitney U-test for continuous variables and as number (percentage) with Fisher's exact test for categorical variables

Table 2 Patient outcomes in the overall cohort $(n=2087)$

\begin{tabular}{lllll}
\hline & $\begin{array}{l}\text { All } \\
\mathbf{N = 2 0 8 7}\end{array}$ & $\begin{array}{l}\text { Women } \\
\mathbf{N = 7 2 6}\end{array}$ & $\begin{array}{l}\text { Men } \\
\boldsymbol{N}=\mathbf{1 3 6 1}\end{array}$ & P value \\
\hline $\begin{array}{l}\text { ICU length of stay } \\
\text { (days) }\end{array}$ & $12[7 ; 21]$ & $12[7 ; 21]$ & $13[7 ; 22]$ & 0.58 \\
$\begin{array}{l}\text { ICU mortality } \\
\text { 28-day mortality }\end{array}$ & $452(21.7 \%)$ & $143(19.7 \%)$ & $309(22.7 \%)$ & 0.11 \\
1-year mortality & $743(21.3 \%)$ & $139(19.2 \%)$ & $304(22.4 \%)$ & 0.09 \\
\hline
\end{tabular}

Data are presented as number (percentage) or median [interquartile range], as appropriate

differences and found inconsistent results [6]. To the best of our knowledge, the present study is the first to assess gender-related differences on long-term outcome of critically ill patients. Our observations are of great interest,

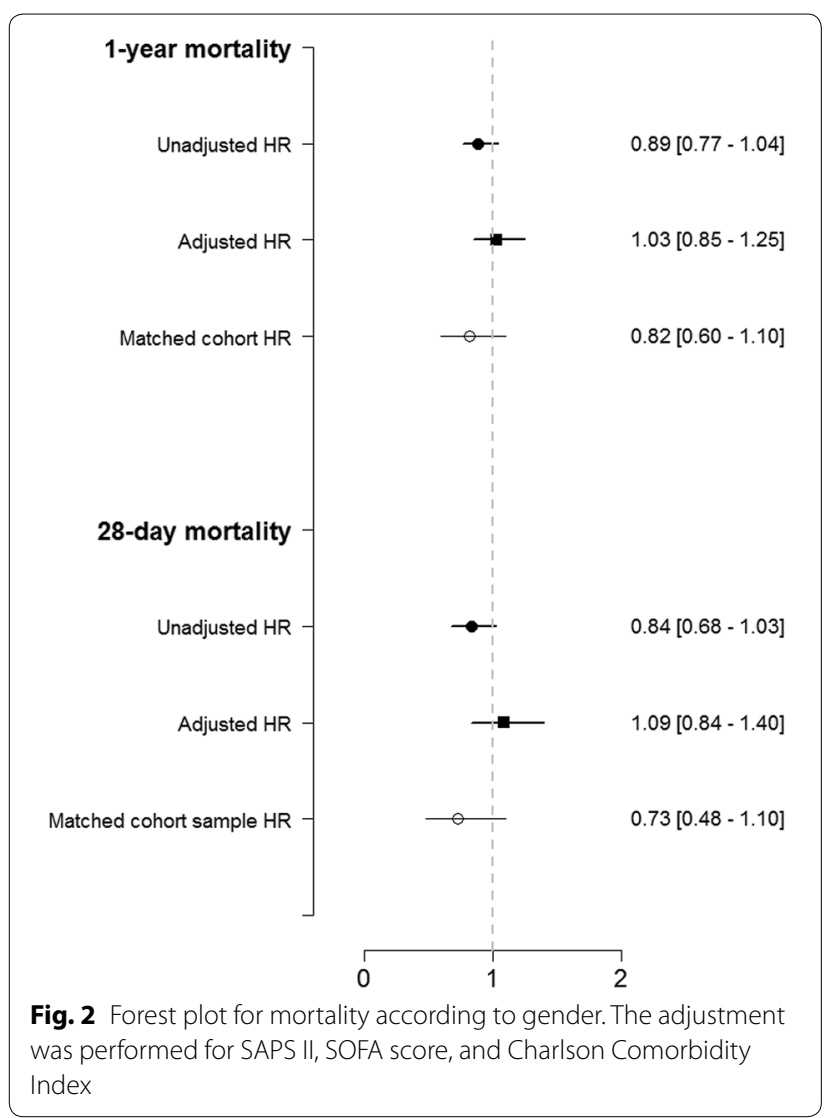

Table 3 Patient outcomes in the propensity scorematched cohort $(n=506)$

\begin{tabular}{lrlll}
\hline & \multicolumn{1}{l}{$\begin{array}{l}\boldsymbol{N}=\mathbf{5 0 6} \\
\text { 28-day mortality }\end{array}$} & $\begin{array}{l}\text { Women } \\
\boldsymbol{N = \mathbf { 2 5 3 }}\end{array}$ & $\begin{array}{l}\text { Men } \\
\boldsymbol{N = 2 5 3}\end{array}$ & $\boldsymbol{P}$ value \\
1-year mortality & $173(34.3 \%)$ & $40(15.8 \%)$ & $53(21 \%)$ & 0.13 \\
\hline
\end{tabular}

Data are presented as number (percentage)

since despite potential differences in genetic, hormonal, and immunological factors-as shown in other conditions [32, 33]-outcomes remain very similar for critically ill patients. Of course, other "non-biological" factors including socioeconomical differences may also have contributed or counterbalanced biological differences. However, a previous study from the FROG-ICU cohort showed a negligible impact of socioeconomic status on survival [32]. Furthermore, despite that a lacking social security coverage was considered an exclusion criterion, only one patient was excluded from the FROGICU cohort for this reason. Further research is needed to explore and distinguish biological from socioeconomical components affecting the long-term outcome of women and men.

From a more clinical point of view, our data support the fact that despite that the gender has been included in several widely used prognostic scores in other fields of medicine [33], none of the commonly used ICU prognostic scores, such as the Acute Physiology and Chronic Health Evaluation (APACHE) II, Simplified Acute Physiology Score (SAPS) II, Multiple Organ Dysfunction Score (MODS), and Sequential Organ Failure Assessment (SOFA), contain gender parameters, which is likely reasonable. Similar outcome between women and men may support the current practice of consistent treatment of the critical illness independently from the gender or, in light of the still severe prognosis of several diseases (i.e., septic shock, cardiogenic shock), a call for the implementation of precision medicine, with regard to differences beyond the gender. Nevertheless, gender-specific admission rates should be viewed as a potential risk of 


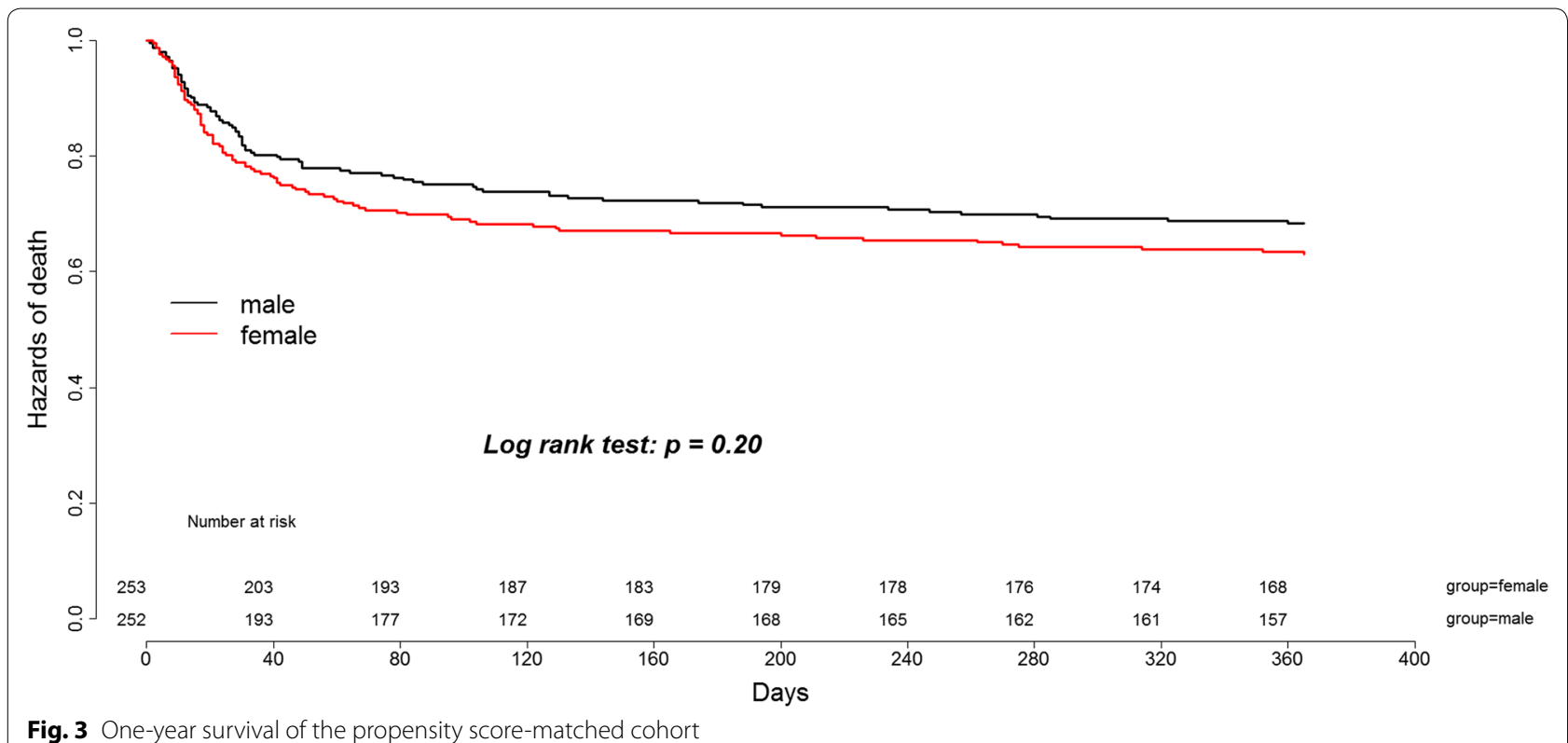

Fig. 3 One-year survival of the propensity score-matched cohort

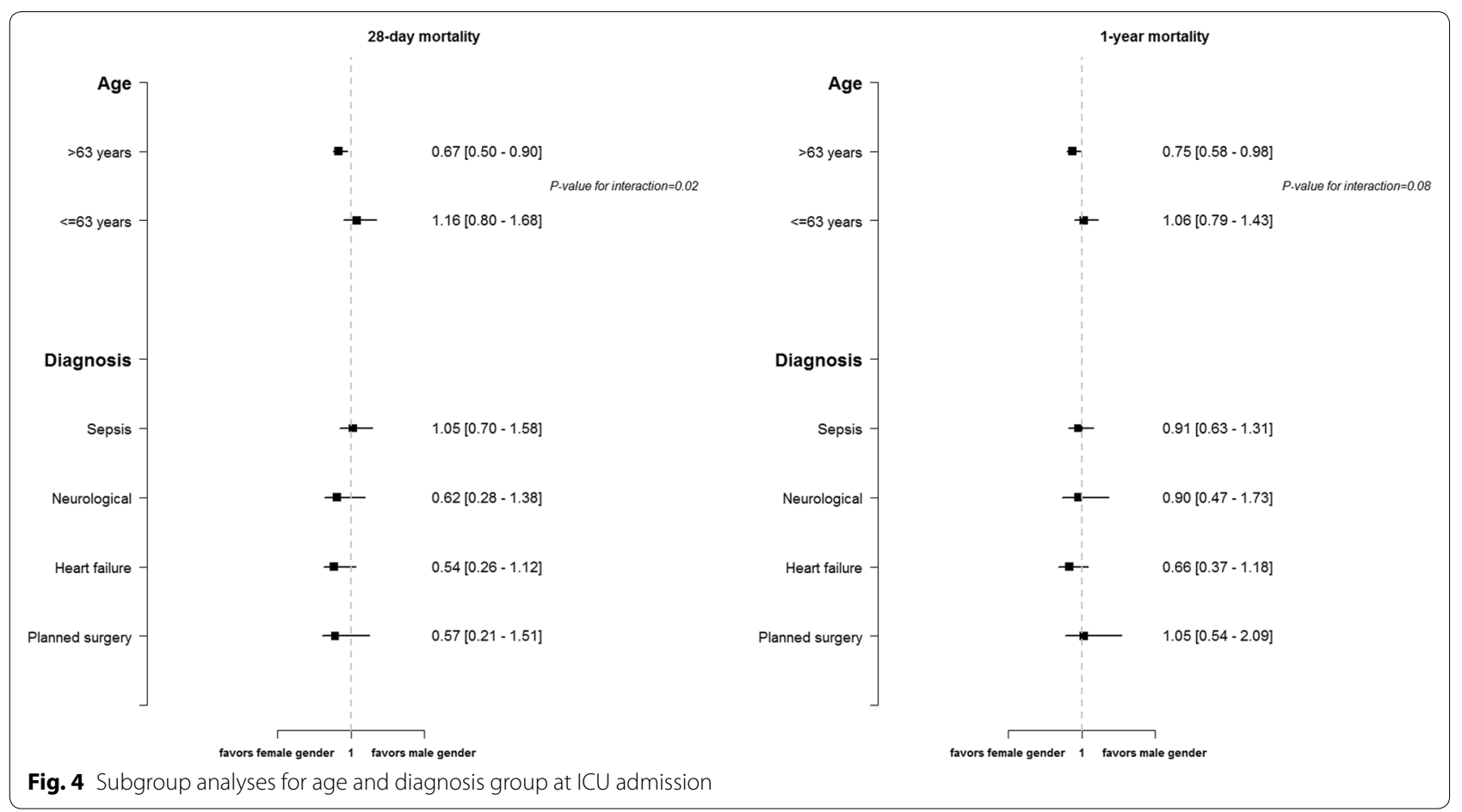

bias since only one-third of patients recruited in FROGICU were female. The male-female ratio in FROG-ICU was slightly more pronounced compared to other studies (Additional file 1: Table 1). If female gender could possibly bias, clinicians against admitting patients to the ICU a "protective" effect of female sex may have been confounded.
Third, our subgroup analysis showed a trend toward a survival benefit for women among elderly subjects. Very notably, older-and not younger-women seem to have a survival benefit compared to men. This observation challenges the current concept of the beneficial effect of estrogens on the incidence of several diseases and survival. This age-dependent differential impact of gender 
on the survival of critically ill patients is a novel finding, and the reasons remain to be elucidated.

We acknowledge that this study suffers from several limits. First, the observational nature of the data hinders confirmation of causality. Secondly, our data lack to account for variables with a substantial impact on the reported results, (i.e., socioeconomic status, patient compliance, and overall behavior (e.g., readiness to assume risk) after hospital discharge. Finally, the cause of death after ICU discharge was not registered in the FROG-ICU study.

\section{Conclusion}

Women constituted one-third of the population of critically ill patients and had similar survival at 28 days and 1 year after ICU admission, independently from comorbidities and disease severity in a large, prospective, multicentric cohort study. Older-and not younger-women may have a survival benefit compared to men. Overall, further research is needed focusing on the outcome before ICU admission, assessment of outcome of prehospital patient care targeting ICU referral, and disease prevalence and severity with respect to gender.

\section{Additional file}

Additional file 1. All figures and tables are originals provided by the statistician (Elodie Féliot)

\section{Authors' contributions}

$M A, E G, A H, A M$ contributed to study concept and design. EG and AM involved in acquisition of data. MA, EG, AH, AM took part in analysis and interpretation of data. MA and AH contributed to drafting of the manuscript. All declared authors took part in critical revision of the manuscript for important intellectual content. EF contributed to statistical analysis. EG and AM obtained funding. EG and AM involved in administrative, technical, or material support. EG and AM contributed to study supervision. All authors read and approved the final manuscript.

\section{Author details}

${ }^{1}$ Department of Anesthesiology, Critical Care and Burn Unit, Hôpitaux Universitaires Saint Louis - Lariboisière, Assistance Publique - Hôpitaux de Paris, Université Paris Diderot - Paris 7, Sorbonne Paris Cité, UMR-S 942, INSERM, Paris, France. ${ }^{2}$ Intensive Care Unit, Assistance Publique - Hopitaux de Paris, University Hospital Ambroise Paré, 26930 Boulogne-Billancourt, France. ${ }^{3}$ Department of Anesthesia, Surgical Intensive Care, Prehospital Emergency Medicine and Pain Therapy, University Hospital Basel, Basel, Switzerland. ${ }^{4}$ Anesthesiology and Perioperative Care Medicine Department, APHP Hopital Beaujon and University, Paris 7, France. ${ }^{5}$ Département d'Anesthésie-Réanimation, UMR 942, Hôpitaux universitaires Paris-Sud, Hôpital de Bicêtre, 78, rue du Général Leclerc, 94270 Le Kremlin-Bicêtre, France. ${ }^{6}$ Service des Réanimations, CHU Nîmes, Place du Pr Robert Debré, 30029 Nîmes Cedex, France. ${ }^{7}$ Department of Anesthesiology and Intensive Care (DAR B), Saint Eloi University Hospital, Montpellier, France. ${ }^{8}$ PhyMedExp, INSERM U-1046, CNRS, Montpellier University, Montpellier, France. ${ }^{9}$ Department of Cardiology, University Hospital Zurich, Zurich, Switzerland. ${ }^{10}$ Department of Anesthesiology and Intensive Care, Saint Louis - Lariboisière University Hospitals, 2 rue Ambroise Paré, 75010 Paris, France. ${ }^{11}$ Department of Anaesthesiology and Critical Care Medicine, AP-HM, Hôpital Nord, Marseille, France.

\section{Acknowledgements}

The authors are particularly grateful to CRAs and healthcare providers of all investigating centers. We also thank the Centre de Recherche Clinique (CRC) of Lariboisière University Hospital for his support.

N. Deye, C. Fauvaux, A. Mebazaa, C. Damoisel, D. Payen, E.Gayat, M. Legrand (Hôpital Lariboisiere, Paris), E. Azoulay, A. S. Moreau, L. Jacob, O. Marie (Hôpital Saint Louis, Paris), M. Wolf, R. Sonneville, R. Bronchard (Hôpital Bichat, Paris), I. Rennuit, C. Paugam (Hôpital Beaujon, Clichy), J. P. Mira, A. Cariou, A. Tesnieres (Hôpital Cochin, Paris), N. Dufour, N. Anguel, L. Guerin, J. Duranteau, C. Ract (Hôpital Bicêtre, Le Kremlin-Bicêtre), M. Leone, B. Pastene (CHU De Marseille, Marseille), T. Sharshar, A. Fayssoyl (Hôpital Raymond Poincare, Garches), J.-L. Baudel, B. Guidet (Hôpital Saint-Antoine), Q. Lu, W. Jie Gu, N. Brechot, A. Combes (Hôpital La Pitie - Salpetriere, Paris), S. Jaber, A. Pradel, Y. Coisel, M. Conseil (CHU St Eloi, Montpellier), A. Veillard-Baron, L. Bodson (Hôpital Ambroise Pare, Boulogne), Jy. Lefrant, L. Elotmani, A. Ayral, S. Lloret (CHU Caremeau, Nimes), S. Pily-Flouri, Jb. Pretalli (Hopital Jean Minjoz, Besançon), Pf. Laterre, V. Montiel, Mf. Dujardin, C. Berghe (Clinique Saint-Luc, Belgium).

\section{Competing interests}

Etienne Gayat received a research grant from Sphingotec, consultancy fees from Magnisense, Roche Diagnostics. Alexandre Mebazaa received speaker's honoraria from Abbott, Novartis, Orion, Roche et Servier and fee as a member of the advisory board and/or Steering Committee from Cardiorentis, Adrenomed, MyCartis, Neurotronik, and Sphingotec. Mattia Arrigo received speaker's honoraria from Orion. All other co-authors have no conflict of interest related to the present manuscript.

\section{Availability of supporting data}

Prof. Mebazaa and Dr. Gayat had full access to all data in the study and take responsibility for the integrity of the data and the accuracy of the data analysis.

\section{Consent for publication}

Not applicable.

\section{Ethical approval and consent to participate}

The study was conducted in France and Belgium in accordance with Good Clinical Practice (Declaration of Helsinki 2002) and Ethical Committee approvals (Comité de Protection des Personnes-lle de France IV, IRB no. 00003835 and Commission d'éthique biomédicale hospitalo-facultaire de l'hôpital de Louvain, IRB no. B403201213352). It is registered on ClinicalTrials.gov (NCT01367093). Patients were included from August 2011 to June 2013.

\section{Funding}

FROG-ICU (ClinicalTrials.gov Identifier NCT01367093) was funded by the Programme Hospitalier de la Recherche Clinique (AON 10-216) and by a research grant from the Société Française d'Anesthésie - Réanimation. Abbott, Sphingotec, Roche Diagnostics, and Critical Diagnostics provided unrestricted free kits to Assistance Publique - Hôpitaux de Paris to conduct biomarker analyses.

\section{Publisher's Note}

Springer Nature remains neutral with regard to jurisdictional claims in published maps and institutional affiliations.

Received: 30 November 2018 Accepted: 6 March 2019

Published online: 29 March 2019

\section{References}

1. Mukhopadhyay A, Tai BC, See KC, Ng WY, Lim TK, Onsiong S, et al. Risk factors for hospital and long-term mortality of critically ill elderly patients admitted to an intensive care unit. Biomed Res Int. 2014;2014:960575.

2. Capuzzo M, Volta C, Tassinati T, Moreno R, Valentin A, Guidet B, et al. Hospital mortality of adults admitted to Intensive care units in hospitals with and without intermediate care units: a multicentre European cohort study. Crit Care. 2014;18(5):551. 
3. Latour J, Lopez-Camps V, Rodriguez-Serra M, Giner JS, Nolasco A, AlvarezDardet C. Predictors of death following ICU discharge. Intensive Care Med. 1990;16(2):125-7.

4. Winters BD, Eberlein M, Leung J, Needham DM, Pronovost PJ, Sevransky JE. Long-term mortality and quality of life in sepsis: a systematic review. Crit Care Med. 2010;38(5):1276-83.

5. Gayat E, Cariou A, Deye N, Vieillard-Baron A, Jaber S, Damoisel C, et al. Determinants of long-term outcome in ICU survivors: results from the FROG-ICU study. Crit Care. 2018;22(1):8.

6. Samuelsson C, Sjoberg F, Karlstrom G, Nolin T, Walther SM. Gender differences in outcome and use of resources do exist in Swedish intensive care, but to no advantage for women of premenopausal age. Crit Care. 2015:19:129.

7. Pietropaoli AP, Glance LG, Oakes D, Fisher SG. Gender differences in mortality in patients with severe sepsis or septic shock. Gend Med. 2010;7(5):422-37.

8. Schoeneberg C, Kauther MD, Hussmann B, Keitel J, Schmitz D, Lendemans S. Gender-specific differences in severely injured patients between 2002 and 2011: data analysis with matched-pair analysis. Crit Care. 2013:17(6):R277.

9. Park J, Jeon $\mathrm{K}$, Chung $\mathrm{CR}$, Yang JH, Cho YH, Cho J, et al. A nationwide analysis of intensive care unit admissions, 2009-2014: the Korean ICU National Data (KIND) study. J Crit Care. 2018;44:24-30.

10. Mebazaa A, Casadio MC, Azoulay E, Guidet B, Jaber S, Levy B, et al. PostICU discharge and outcome: rationale and methods of The French and euRopean Outcome reGistry in Intensive Care Units (FROG-ICU) observational study. BMC Anesthesiol. 2015:15:143.

11. Reinikainen $M$, Niskanen M, Uusaro A, Ruokonen E. Impact of gender on treatment and outcome of ICU patients. Acta Anaesthesiol Scand. 2005;49(7):984-90.

12. Raine R, Goldfrad C, Rowan K, Black N. Influence of patient gender on admission to intensive care. J Epidemiol Community Health. 2002;56(6):418-23.

13. Parissis JT, Mantziari L, Kaldoglou N, Ikonomidis I, Nikolaou M, Mebazaa A, et al. Gender-related differences in patients with acute heart failure: management and predictors of in-hospital mortality. Int J Cardiol. 2013;168(1):185-9.

14. Gevaert SA, de Bacquer D, Willems AM, Vande Kerckhove B, Weytjens C, van Camp G, et al. Gender differences in the management and outcome of atrial fibrillation complicating acute heart failure. J Card Fail. 2014;20(6):431-7.

15. Sederholm Lawesson S, Isaksson RM, Thylen I, Ericsson M, Angerud K, Swahn E, et al. Gender differences in symptom presentation of ST-elevation myocardial infarction: an observational multicenter survey study. Int J Cardiol. 2018;264:7.

16. Mazurek M, Huisman MV, Rothman KJ, Paquette M, Teutsch C, Diener $\mathrm{HC}$, et al. Gender differences in antithrombotic treatment for newly diagnosed atrial fibrillation: the GLORIA-AF registry program. Am J Med. 2018:131:945.

17. Raccah BH, Perlman A, Zwas DR, Hochberg-Klein S, Masarwa R, Muszkat $M$, et al. Gender differences in efficacy and safety of direct oral anticoagulants in atrial fibrillation: systematic review and network meta-analysis. Ann Pharmacother. 2018:52:1135.

18. Kollia N, Panagiotakos DB, Chrysohoou C, Georgousopoulou E, Tousoulis $D$, Stefanadis $C$, et al. Determinants of healthy ageing and its relation to 10-year cardiovascular disease incidence: the ATTICA study. Cent Eur J Public Health. 2018;26(1):3-9.

19. Josiah A, Farshid A. Gender is not a predictor of mortality or major adverse cardiovascular events in patients undergoing percutaneous coronary intervention for acute coronary syndromes. Heart Lung Circul. 2018. https://doi.org/10.1016/j.hlc.2018.03.020

20. Kuck KH, Brugada J, Furnkranz A, Chun KRJ, Metzner A, Ouyang F, et al. Impact of female sex on clinical outcomes in the FIRE AND ICE trial of catheter ablation for atrial fibrillation. Circ Arrhythm Electrophysiol. 2018;11(5):e006204.

21. Magnussen C, Ojeda FM, Wild PS, Sorensen N, Rostock T, Hoffmann BA, et al. Atrial fibrillation manifestations risk factors and sex differences in a population-based cohort (From the Gutenberg Health Study). Am J Cardiol. 2018;122:76.

22. Her AY, Shin ES, Kim YH, Garg S, Jeong MH. The contribution of gender and age on early and late mortality following ST-segment elevation myocardial infarction: results from the Korean Acute Myocardial Infarction National Registry with Registries. J Geriatr Cardiol. 2018;15(3):205-14.

23. Nozaki A, Shirakabe A, Hata N, Kobayashi N, Okazaki H, Matsushita M, et al. The prognostic impact of gender in patients with acute heart failure: an evaluation of the age of female patients with severely decompensated acute heart failure. J Cardiol. 2017;70(3):255-62.

24. Potocnjak I, Bodrozic-Dzakic T, Smit I, Trbusic M, Milosevic M, Degoricija V. Gender-associated differences in acute heart failure patients presenting to Emergency Department. Acta Clin Croat. 2015;54(3):257-65.

25. Meyer EC, Konecky B, Kimbrel NA, DeBeer BB, Marx BP, Schumm J, et al, Gender differences in associations between DSM- 5 posttraumatic stress disorder symptom clusters and functional impairment in war veterans. Psychol Serv. 2018;15(2):230-7.

26. Husky MM, Mazure CM, Kovess-Masfety V. Gender differences in psychiatric and medical comorbidity with post-traumatic stress disorder. Compr Psychiatry. 2018;84:75-81.

27. Iurato S, Carrillo-Roa T, Arloth J, Czamara D, Diener-Holzl L, Lange J, et al. DNA methylation signatures in panic disorder. Transl Psychiatry. 2017;7(12):1287.

28. Gunzenhauser C, Saalbach H, von Suchodoletz A. Boys have caught up, family influences still continue: influences on executive functioning and behavioral self-regulation in elementary students in Germany. Psych J. 2017:6(1):29-42.

29. Rzeszutek M. Health-related quality of life and coping strategies among people living with HIV: the moderating role of gender. Arch Womens Ment Health. 2017;21:2247.

30. Park DI, Stambuk J, Razdorov G, Pucic-Bakovic M, Martins-de-Souza D, Lauc G, et al. Blood plasma/lgG N-glycome biosignatures associated with major depressive disorder symptom severity and the antidepressant response. Sci Rep. 2018;8(1):179.

31. Wiktorsson S, Rydberg Sterner T, Mellqvist Fassberg M, Skoog I, Ingeborg Berg A, Duberstein P, et al. Few sex differences in hospitalized suicide attempters aged 70 and above. Int J Environ Res Public Health. 2018;15(1):141.

32. Bastian K, Hollinger A, Mebazaa A, Azoulay E, Feliot E, Chevreul K, et al. Association of social deprivation with 1-year outcome of ICU survivors: results from the FROG-ICU study. Intensive Care Med. 2018:44(12):2025-37.

33. Chen JY, Zhang AD, Lu HY, Guo J, Wang FF, Li ZC. CHADS2 versus CHA2DS2-VASC score in assessing the stroke and thromboembolism risk stratification in patients with atrial fibrillation: a systematic review and meta-analysis. J Geriatr Cardiol. 2013;10(3):258-66.

\section{Submit your manuscript to a SpringerOpen ${ }^{\circ}$ journal and benefit from:}

- Convenient online submission

- Rigorous peer review

- Open access: articles freely available online

- High visibility within the field

Retaining the copyright to your article

Submit your next manuscript at springeropen.com 